\title{
ARTIGOS
}

\section{APLICACÃO DE PROJETOS DE DESIGN NA GESTÃO DE RESÍDUOS DA UFSC}

\section{APPLICATION OF DESIGN PROJECTS IN THE WASTE MANAGEMENT OF THE FEDERAL UNIVERSITY OF SANTA CATARINA}

\section{ANA VERONICA PAZMINO, Dra.|UFSC}

\begin{abstract}
RESUMO
Este artigo apresenta o resultado da ação de um projeto de extensão cujo objetivo era desenvolver ações por meio do Design para a Gestão de Resíduos da UFSC e do NDI (Núcleo de Desenvolvimento Infantil). Atendendo a demanda da universidade que conforme previsto na Política Nacional de Resíduos Sólidos (PNRS), Lei 12.305 de 2010, está sujeita à elaboração do Plano de Gerenciamento de Resíduos Sólidos (PGRS), pois a composição, natureza e volume de seus resíduos sólidos gerados diferem dos resíduos domiciliares de responsabilidade do Poder Público. $\mathrm{O}$ artigo mostra que por meio do envolvimento de alunos bolsistas, alunos voluntários e alunos da disciplina de metodologia de projeto do curso de Design e Design de Produto, foram projetados e produzidos diversos objetos: coletores binários para a área externa do campus, jogos para sensibilizar pessoas em relação ao descarte adequado, material para valorização dos catadores e material para auxiliar na educação ambiental do NDI.
\end{abstract}

PALAVRAS CHAVE: Gestão de resíduos; design; ação de extensão

\begin{abstract}
This paper presents the result of the action of the extension project whose objective was to develop actions through Design for Waste Management at UFSC and NDI (Child Development Center). Meeting the demand of the university which, as provided for in the National Solid Waste Policy (PNRS), Law 12,305 of 2010, is subject to the preparation of the Solid Waste Management Plan (PGRS), because the composition, nature and volume of its solid waste generated differs from household waste under the responsibility of the government. The work shows that through the involvement of scholarship students, volunteer students and students of the project methodology discipline, various objects were designed and produced: binary bins for the external area of the campus, games to sensitize people in relation to proper disposal, material for valuing waste pickers and material to assist in the environmental education of NDI.
\end{abstract}

KEY WORDS: Waste management; design; extension action 


\section{INTRODUÇÃO}

Um dos principais problemas ambientais do nosso século é a geração de resíduos sólidos. Com a Revolução Industrial e o capitalismo industrial os padrões de consumo se intensificaram rapidamente. $\mathrm{O}$ ato de produzir, consumir e descartar cresceram em ritmo muito mais acelerado do que a capacidade de absorção da natureza. Nas últimas décadas observa-se que essa relação predatória gera uma série de impactos ambientais e a partir disso medidas relacionadas ao tema passaram a ter destaque em todo o mundo.

No Brasil, a maior parte dos RSU Resíduos Sólidos Urbanos coletados segue para disposição em aterros sanitários, tendo registrado um aumento de 10 milhões de toneladas em uma década, passando de 33 milhões de toneladas por ano para 43 milhões de toneladas em 2019. Por outro lado, a quantidade de resíduos que segue para unidades inadequadas (lixões e aterros controlados) também cresceu, passando de 25 milhões de toneladas por ano para pouco mais 29 milhões de toneladas por ano. (ABRELPE, 2020, p.20)

Segundo o relatório (ABRELPE, 2020) No Brasil em 2020 foram gerados 79,6 milhões de toneladas de RSU o que corresponde a geração de 221 mil toneladas de resíduos por dia. O relatório alerta que "o país apresenta uma curva ascendente e tem registrado aumento tanto nas quantidades totais, quanto nos valores per capita".

Especificamente na cidade de Florianópolis, o total de resíduos coletados em 2018 pela COMCAP, empresa pública concessionária dos serviços de limpeza urbana em Florianópolis, foi de 209 mil toneladas, o que corresponde à média de 600 toneladas por dia ou 17,5 mil toneladas por mês. COMCAP (2020). Na Universidade Federal de Santa Catarina (UFSC), a comunidade universitária produz mensalmente cerca de 140,9 toneladas de resíduos convencionais (recicláveis, rejeitos e orgânicos).

A Secretaria de Gestão de Resíduos Sólidos da UFSC está se ajustando desde 2014, devido a uma autuação da vigilância sanitária, às leis e políticas ambientas do país como previsto no Decreto $n^{\circ}$. 5.940/2006 (BRASIL, 2006), que institui a Coleta Seletiva Solidária como a separação dos resíduos recicláveis descartados pelos órgãos e entidades da administração pública federal direta e indiretamente, na fonte geradora, e sua destinação às associações e cooperativas dos catadores de materiais recicláveis.

Atualmente não há coleta seletiva na universidade, nem um sistema de coletores adequado que visa a separação dos diferentes resíduos descartados. Porém, com o novo Plano de Gerenciamento de Resíduos Sólidos (PGRS) que está sendo elaborado pela gestão dos resíduos sólidos da UFSC, o sistema de Coleta Seletiva Solidária (CSS) há necessidade de aquisição de coletores binários.

Como não há a segregação na fonte, constata-se que apenas os rejeitos ( 1,3 toneladas das 4,7 toneladas diárias) deveriam ser destinados ao aterro sanitário. A mistura e a mesma destinação de todos esses resíduos o transformam em lixo sem valor. Sendo assim, surge a urgência em implementar a CSS e repensar novos coletores para o campus para que ocorra corretamente a segregação desses resíduos.

Atualmente os tipos de coletores externos da UFSC não seguem um padrão. Há coletores simples, coletores seletivos, tubos de concreto, coletores específicos do CTC (Centro Tecnológico), entre outros. Nenhum segue as reais necessidades dos usuários e do campus e todos apresentam alguma deficiência. A grande maioria apresenta baixa resistência ao sol e à chuva, consequentemente quebram e/ou enferrujam com o decorrer do tempo. Também não possuem cesto interno, o que dificulta/impede a limpeza adequada. A maioria não possui proteção contra a entrada e acúmulo de chuva, nem cuidado com a higiene. E nenhum dos coletores é basculante, característica que preza a saúde e praticidade do trabalhador.

As universidades possuem um papel importante na construção de uma conscientização ambiental, têm a missão de difundir a cultura da reciclagem e combater a invisibilidade dos trabalhadores que manuseiam esses resíduos diariamente. A UFSC está se inserindo nesse contexto a fim de valorizar os serviços ambientais dos catadores, oferecer melhores condições de trabalho, aplicar mudanças culturais positivas junto à comunidade e conscientizar da geração ao descarte dos resíduos sólidos. A mobilização da comunidade universitária também será indispensável para sustentar as futuras ações aplicadas.

O papel do design e suas vertentes, como o design de produto, há muito representa um meio de abordar e gerar ações positivas quanto às temáticas sociais e ambientais. O presente artigo mostra como o design pode realizar um trabalho junto da comunidade por meio de um projeto de extensão e ação de ensino.

\section{METODOLOGIA PROJETUAL}

O processo projetual que foi adotado para o desenvolvimento dos projetos foi o Design Thinking, onde as pessoas são colocadas em primeiro lugar com ênfase em suas necessidades fundamentais. "O design thinking se baseia em nossa capacidade de ser intuitivos, reconhecer padrões, 
desenvolver ideias que tenham um significado emocional além do funcional, nos expressar em mídias além de palavras ou símbolos". (BROWN, 2009).

Esse processo é fundamentalmente exploratório, sem um roteiro sequencial de passos ordenados, há apenas pontos de partidas e pontos de referências ao longo do trajeto. Para Brown, a equipe de design deveria transitar por estes três espaços ao longo do projeto: um espaço de "Inspiração" ou "Imersão" que é o problema ou a oportunidade que motiva a busca por soluções; pela "Idealização" ou "Ideação" que é o processo de gerar, desenvolver e testar ideias; e o espaço de "Implementação" ou "Prototipação" que seria o caminho que vai do estúdio de design ao mercado. A figura 01 mostra o esquema do processo do Design Thinking.

$\mathrm{Na}$ fase de Imersão a equipe de projeto (coordenadora, alunos bolsistas, alunos voluntários e os alunos da disciplina de metodologia de projeto) se aproximaram do contexto do problema e os insights foram coletados de todas as fontes possíveis.

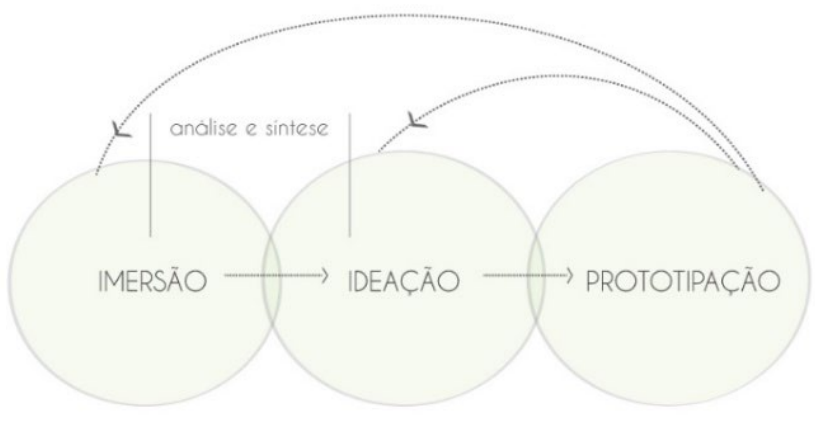

Figura 01 - Esquema do Design Thinking

Fonte: Adaptado de (VIANNA, 2012)

A Imersão pode ser dividida em duas etapas: Preliminar e em Profundidade. A primeira tem como objetivo o reenquadramento e o entendimento inicial do problema, enquanto a segunda destina-se à identificação de necessidades e oportunidades que irão nortear a geração de soluções na fase seguinte do projeto, a de Ideação. VIANNA (et al. 2012).

Segundo Brown (2010), essa fase deve focar em insight, observação e empatia. "O insight é uma das principais fontes do design thinking, e em geral não provém do âmbito dos dados quantitativos que mensuram exatamente o que já temos e nos dizem o que já sabemos". (BROWN, 2010). Sair pelo mundo e observar as verdadeiras experiências dos usuários pode ser o ponto de partida.

Para Brown (2010) construímos pontes de insight através da empatia, que é a tentativa de ver o mundo através dos olhos das outras pessoas e colocar-se no lugar delas.
Porém, faz-se necessário estender a compreensão não somente às interações sociais das pessoas em grupos, mas sim às interações entre os próprios grupos. O Design Thinking deve abranger a inteligência coletiva e conciliar consumidores e criadores através da colaboração. Dessa forma que chegaremos à definição e entendimento do público-alvo, junto com a elaboração de análise etnográfica.

Na segunda fase denominada Ideação, "utiliza-se as ferramentas da fase anterior com a finalidade de estimular a criatividade e gerar alternativas que estejam de acordo com o contexto do projeto". (VIANNA, et al. 2012). Nessa fase de geração de alternativas fala-se da técnica do brainstorming, que serve para explorar a capacidade criatividade de um indivíduo ou grupo. A realização de protótipos iniciais ocorre também nessa etapa com o intuito de validar algumas de suas características antes que o plano venha a ser construído definitivamente.

E por fim a fase da Prototipação onde foram validadas as ideias e que em alguns projetos aconteceram paralelamente à Imersão e à Ideação. Para Brown (2010), o objetivo dos protótipos iniciais deve ser decidir se uma ideia tem valor funcional ou não, uma das maneiras de adquirir essas respostas é apresentando os protótipos aos possíveis usuários para obter feedbacks. A figura 02 mostra o ciclo iterativo da prototipação.

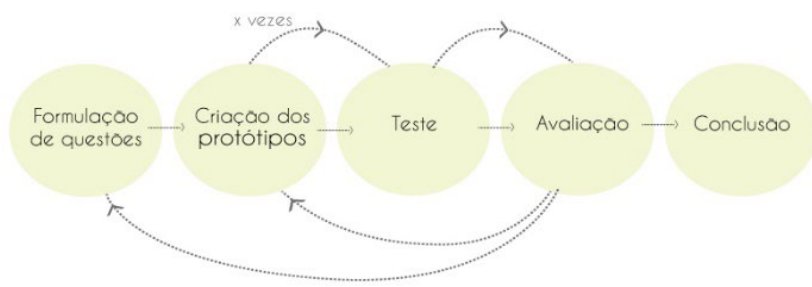

Figura 02 - Ciclo de prototipação Fonte: Adaptado de (VIANNA, 2012)

A seguir é tratado o tema da extensão universitária sendo que a relação de ensino e extensão fazem parte do processo de ensino-aprendizagem da disciplina de metodologia de projeto.

\section{EXTENSÃO UNIVERSITÁRIA}

Seu escopo é o de um processo interdisciplinar, educativo, cultural, científico e político, por meio do qual se promove uma interação que transforma não apenas a Universidade, mas também os setores sociais com os quais ela interage.

Extensão Universitária denota também prática acadêmica, a ser desenvolvida, como manda a Constituição de 1988, de forma indissociável com o Ensino e a Pesquisa, com vistas à promoção e garantia dos valores democráticos, da 
equidade e do desenvolvimento da sociedade em suas dimensões humana, ética, econômica, cultural, social. Política Nacional de Extensão Universitária (2012).

Na RESOLUÇÃO No 7, DE 18 DE DEZEMBRO DE 2018 (MEC) se estabelece no "Art. 40 As atividades de extensão devem compor, no mínimo, 10\% (dez por cento) do total da carga horária curricular estudantil dos cursos de graduação, as quais deverão fazer parte da matriz curricular dos cursos".

Neste artigo a ação de extensão universitária mostra que pode fazer parte do ensino em cursos de design, como uma prática de inserção do futuro designer para ter a sensibilidade e empatia visando atender as necessidades de grupos que saem da curva dos interesses empresariais na busca de equidade e do desenvolvimento da sociedade.

Articulação da extensão no ensino se dá com a disciplina de Metodologia de projeto em que o inicio da prática projetual incentiva os alunos para o desenvolvimento de soluções atendendo ao projeto de extensão.

A seguir são mostrados os resultados dos alunos em que muitos foram aplicados e entregues em quanto outros ficaram como projetos até haver verba ou financiamento para sua implementação.

\section{RESULTADOS}

Em 2017 o enunciado do projeto foi: Desenvolvimento de material gráfico ou objetos que visem sensibilizar, informar e educar alunos, servidores e comunidade sobre as formas adequadas de descarte do resíduo sólido. Lixeiras binárias, terciarias, quaternárias, material informativo e/ou jogos. Foram desenvolvidos diversos objetos para o projeto de extensão "Gestão de Resíduos no Campus da UFSC".

Neste artigo são mostradas quatro soluções que representam a ação para diversos públicos, sendo eles: adultos que frequentam o campus e crianças do NDI -Núcleo de Desenvolvimento Infantil e de creche pública. As soluções embora diferentes têm o mesmo o objetivo, contribuir com a informação sobre o descarte adequado de resíduos por meio da educação ambiental.

\subsection{Coletores binários externos}

Foi identificado que os resíduos orgânicos gerados pela comunidade acadêmica e que são descartados nos coletores externos do campus não sofrem segregação e recebem o mesmo acondicionamento e destino que os demais resíduos.

Os rejeitos, são os materiais que não podem ser reaproveitados, representam $27 \%$ do resíduo gerado no campus da UFSC. Eles são originados em todos os centros de ensino, incluindo o Colégio Aplicação e o NDI Núcleo de Desenvolvimento infantil que atende crianças de 0 a 5anos 8 meses, as Unidades Administrativas, lanchonetes, espaços públicos, etc., e são misturados com todos os materiais recicláveis que não sofrem a segregação informal.

Todos os resíduos convencionais que são descartados nas áreas externas do campus, sem qualquer tipo de segregação, são retirados diariamente dos coletores e ensacados por empregados da empresa contratada PROVAC.

Posteriormente as sacolas são recolhidas e encaminhadas, por dois funcionários da UFSC, para um mesmo ponto de coleta (contêiner) situado próximo à prefeitura universitária. A coleta final ocorre diariamente no período noturno, pela empresa COMCAP por meio do contrato 284/2011. Após a coleta esses resíduos são destinados ao aterro sanitário de Biguaçu que se encontra no continente.

A estrutura existente atualmente no campus conta com 232 coletores externos e 16 pontos de coleta, com 350 contentores de $240 \mathrm{~L}$ distribuídos, e 2 contêineres de $21 \mathrm{~m}^{3}$ para o excedente. Esses coletores externos apresentam uma série de problemas como identificabilidade, durabilidade, resistência, qualidade sanitária, e de adequação às condições de uso.

No contexto de mobiliário urbano a identificabilidade diz respeito ao reconhecimento de um objeto como tal, a facilidade do usuário em reconhecer de forma rápida e eficaz o mobiliário em questão. $\mathrm{O}$ conjunto de coletores do campus apresenta grandes problemas de identificabilidade, e isso acontece quando o descartador confunde uma lixeira com outro objeto. No caso da UFSC a inexistência de um padrão de coletores e a clareza de significado podem ser alguns dos fatores de descarte de resíduos de forma inadequada. Na Figura 03 pode-se observar a ausência de um padrão único, através de cores, formas e materiais.

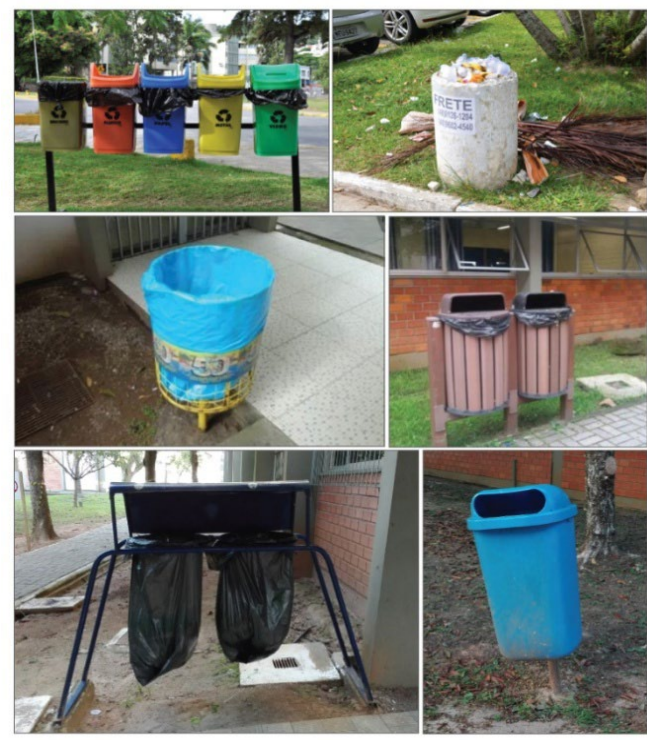

Figura 03-Coletores externos da UFSC Fonte: Préve, 2017 
Os coletores apresentam configuração muito diferente uma da outra e isso gera confusão no momento do descarte pela falta de uma configuração visual característica.

Além da existência de padrão é recomendável que o objeto tenha a aparência condizente com a sua função, ou seja, que possua elementos comuns àquele tipo de produto, senão o usuário terá dificuldade de identificá-lo e passará a utilizá-lo de maneira inadequada ou a ignorá-lo.

No Campus da UFSC foram encontrados diferentes usos do mesmo objeto: Os tubos de concreto. Dentre os mais diversos tipos de coletores do campus esse é o mais comum, porém há uma variedade de usos do mesmo, são usados como suporte para plantas, e também como barreiras para passagens de pedestres.

Os coletores em tubo de concreto apresentam tamanhos, alturas e diâmetro da boca muito distintas umas das outras. Foram encontradas alturas entre $550 \mathrm{~mm}$ e $1100 \mathrm{~mm}$, e os diâmetros variando entre $250 \mathrm{~mm}$ e $600 \mathrm{~mm}$.

Quanto aos problemas de higiene foi verificado que a grande maioria não possui tampa ou se a mesma se encontra quebrada. Algumas apresentam mau cheiro, além de ausência de sacolas na maior parte delas.

Foi feita uma pesquisa no campus, a figura 04 mostra o infográfico com a síntese dos dados da pesquisa.

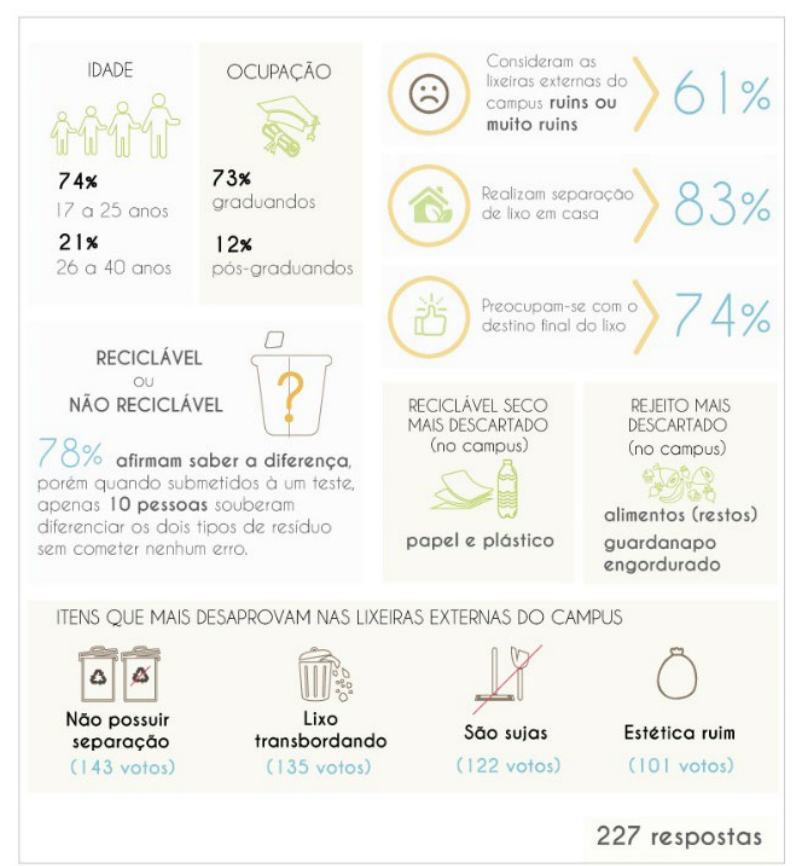

Figura 04- Infográfico da pesquisa

Fonte: Préve, 2017

O questionário foi aplicado através de ferramenta online Typeform, do dia 29 de setembro ao dia 05 de outubro de 2017, e divulgado através de mídias sociais para toda a comunidade acadêmica. Foram elaboradas 18 alternativas de múltipla escolha e 1 aberta, onde obteve-se um total de 227 respostas.

$61 \%$ consideram os coletores ruins, desaprovam os resíduos transbordando. Foi realizado um registro fotográfico de observação mostrando os problemas dos funcionários para retirar os resíduos dos coletores. A figura 05 mostra a ação dos funcionários.

È clara a postura indaquada dos funcionários, a coleta dos résiduos com as mãos e o esforço para retirar de todos os coletores do campus quando estes não tem sacolas.
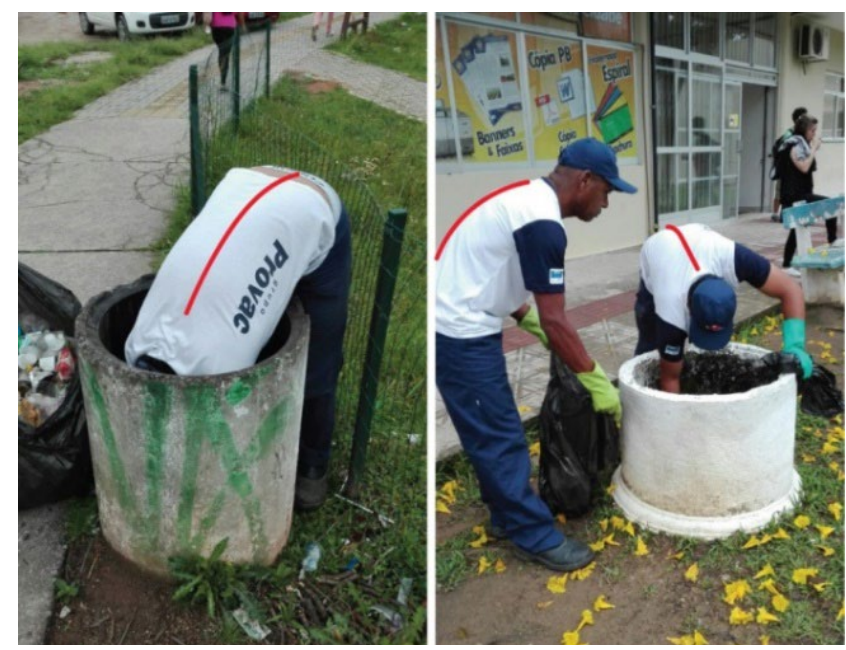

Figura 05: Postura dos trabalhadores na retirada de resíduos-Coletor de tubo de concreto Fonte: Préve, 2017

Após a definição de requisitos de projeto, foram geradas alternativas de coletores com tampa, altura adequa$\mathrm{da}$, material concreto por ser de mais baixo custo e resistente a intempérie. A figura 06 mostra a identidade proposta para os coletores binários.

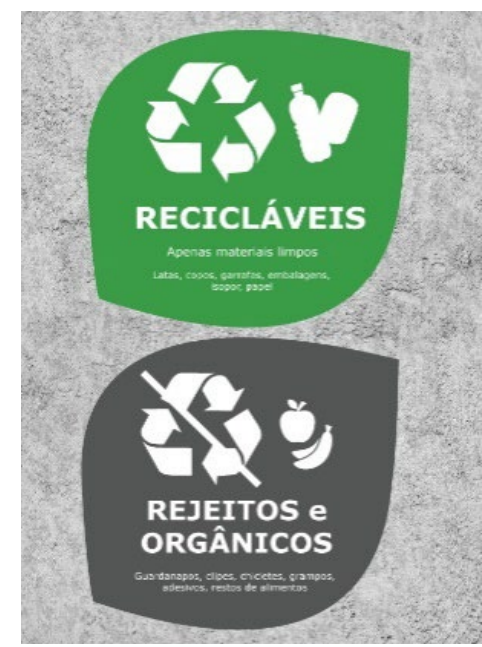

Figura 06- Letreiros de identificação do resíduo Fonte: Préve, 2017 
A figura 07 mostra o render dos coletores binários escolhidos e refinados. Eles ainda não foram produzidos por falta de verba da gestão de resíduos da UFSC e por falta de parcerias com empresas que possam confeccionar os coletores a um baixo custo.

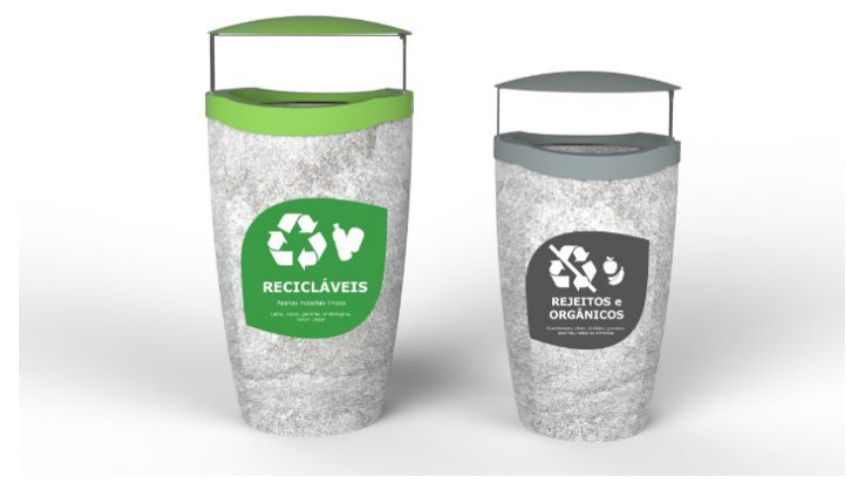

Figura 07- Render Coletores binários Fonte: Préve, 2017

Os coletores apresentam uma tampa metálica de simples manuseio, pois seria facilmente aberta até sua posição final, e seu retorno à posição inicial também é bastante simplificado, havendo auxílio da haste de apoio para que a tampa permaneça no ponto definido.

Os coletores dos recicláveis seco e a de rejeitos e orgânicos possuem respectivamente $830 \mathrm{~mm}$ e $730 \mathrm{~mm}$ de altura até a abertura da boca. Essas dimensões foram aplicadas para não comprometer a saúde física do trabalho no movimento de retirada e reposição das sacolas. Além disso, possuem altura confortável para a realização do movimento de descarte por parte dos usuários.

Os coletores são compostos por um corpo de concreto armado. As outras peças se sugere sejam fabricadas em aço inoxidável, sendo elas: um aro para sobrepor na boca da lixeira; uma tampa côncava com haste de reforço na parte interna; duas hastes soldadas à tampa, uma servindo apenas como apoio e outra como sustentação; e uma dobradiça na haste de sustentação.

\subsection{Material de ensino para o NDI/UFSC}

Para o desenvolvimento do material de ensino para o tema gestão de resíduos, para o NDI, os alunos entraram em contato com a professora Carolina da Educação Ambiental que manifestou a necessidade para desenvolver um jogo que ensinasse as crianças a forma correta de descarte nos coletores binários internos que foram confeccionados na marcenaria da UFSC.
A dinâmica devia ser lúdica e divertida, além disso, foi solicitado que fosse desenvolvido um painel para a Horta e uma forma de identificar as plantas 24 plantas que tem no canteiro. A figura 08 mostra o infográfico que surgiu da pesquisa realizada no NDI.

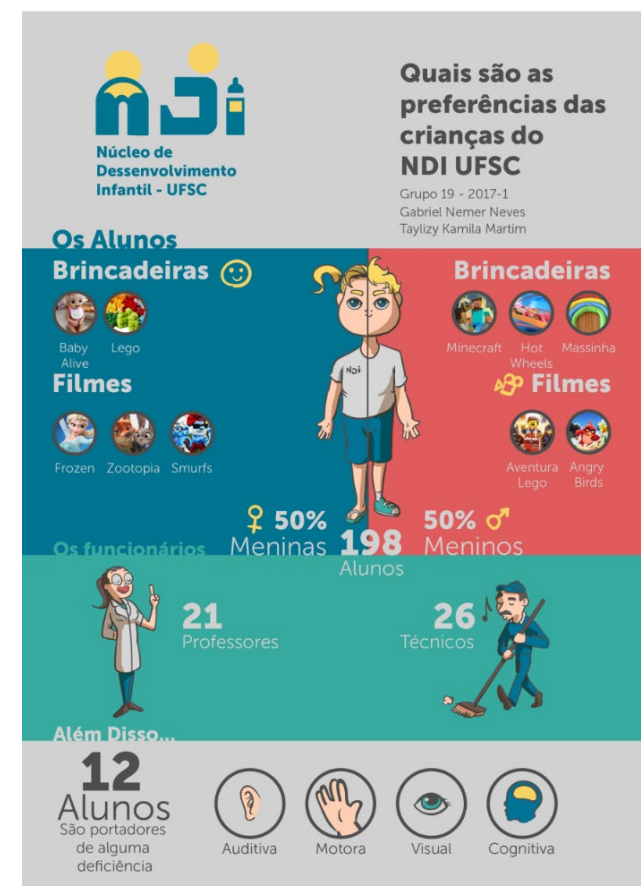

Figura 08 - Infográfico NDI Fonte: Nemer, 2018

Foi desenvolvido um jogo de tabuleiro Cata-quí em que o cenário é uma praia que faz parte do repertorio das crianças, já que Florianópolis é uma ilha e desde pequenas as crianças frequentam este local. Nesse cenário onde habitam animais como a coruja buraqueira, gaivota, sururu, siri, estrela do mar, tartaruga cabeçuda e o ouriço, tem seu espaço ocupado por diversos resíduos orgânicos, recicláveis e rejeitos.

As ilustrações dos animais foram colocadas em peças de madeira. Os animais da praia estão na figura 09.

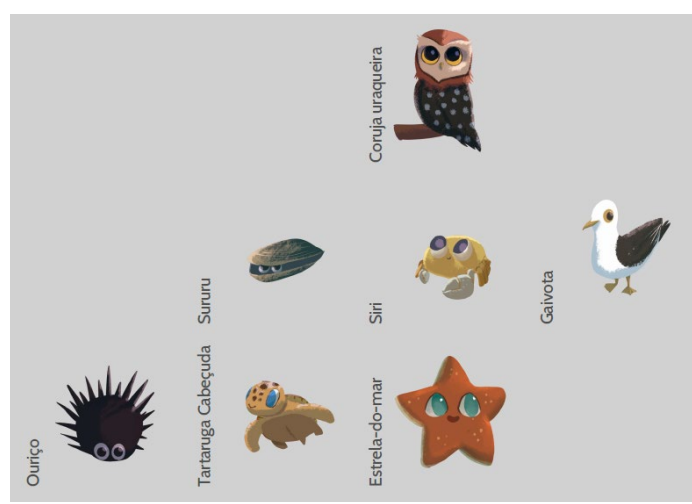

Figura 09 - Animais do jogo Cata-quí Fonte: Nemer, 2018 
A dinâmica do jogo mostra os resíduos que ocupam a praia por terem sido descartados de forma inadequada são objetos e embalagens que fazem parte do repertório das crianças. Todo os resíduos são adesivos colados em peças que são jogados no tabuleiro enquanto a professora diz o nome do objeto ou resíduo e as crianças tem que procurar e pegar e descartar no coletor binário (rejeitos e recicláveis). As imagens dos resíduos estão na figura 10.

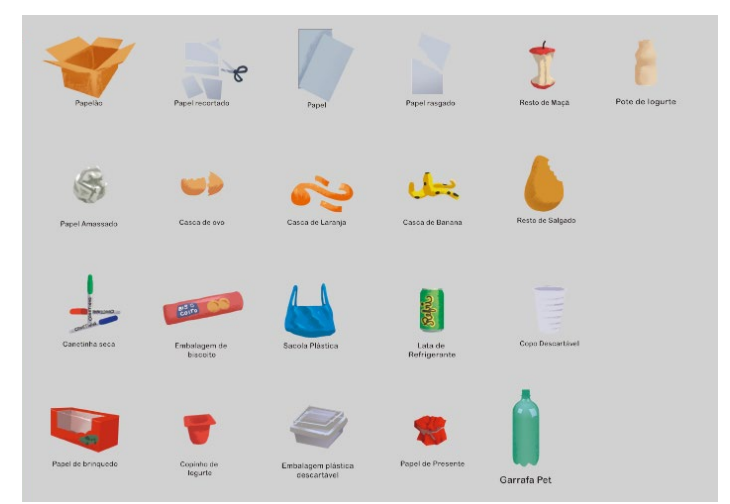

Figura 10-Resíduos

Fonte: Nemer, 2018

A figura 11 e 12 mostram o jogo finalizado e o mesmo sendo jogado no NDI onde foi entregue à professora e onde as crianças brincaram e interagiram. Algumas alterações foram solicitadas como: retirar a lata de refrigerante já que não consumem no NDI e escrever no verso das fichas o nome do animal e resíduos já que algumas crianças queriam ler, mesmo que ainda não sejam alfabetizadas. Tornando possível que o jogo seja adequado para crianças de outras faixas etárias. As crianças gostaram de brincadeira, todos/todas participaram. Cabe mencionar que os coletores se tornam a embalagem para as peças que ficam aí guardadas.

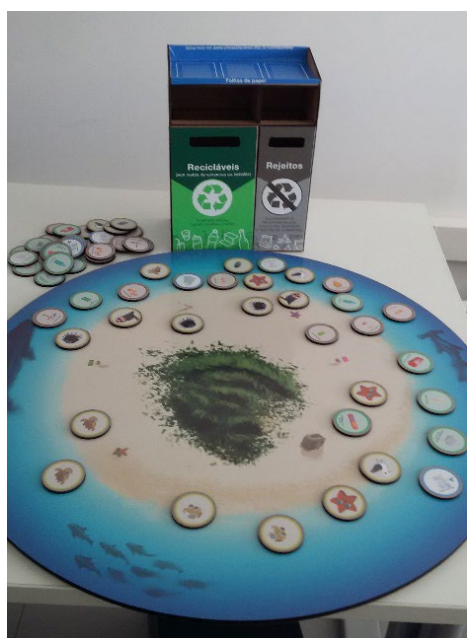

Figura 11- Jogo Cata-quí Fonte: Pazmino, 2018
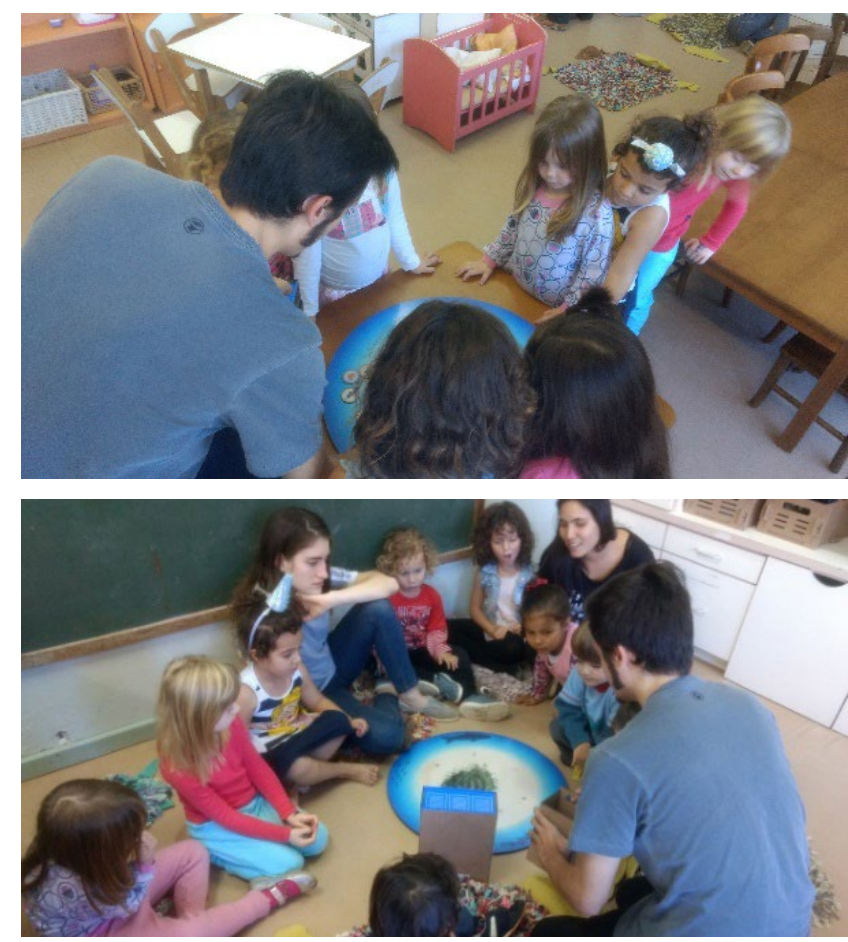

Figura 12- Jogo Cata-quí no NDI Fonte: Pazmino, 2018

Além do jogo de tabuleiro também foi criado o painel da horta do NDI e o sistema de identificação das plantas para a horta por meio de números que devem ser fixados na terra. O painel foi confeccionado e feita a instalação. A figura 13 mostra o painel Horta da Vovô e a figura 14 os números que foram confeccionados com material reutilizado e por meio de corte a laser no laboratório pronto 3D da UFSC.

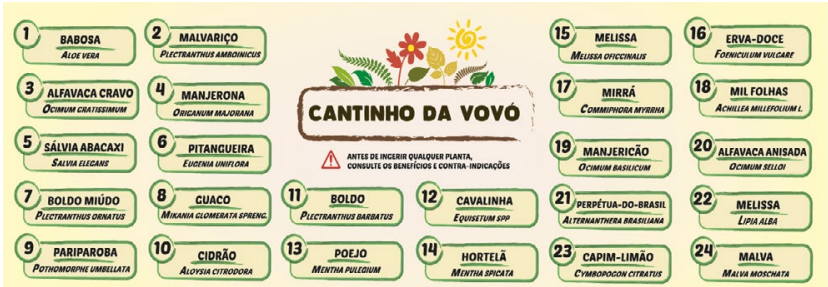

Figura 13- Painel Horta da Vovô Fonte: Pazmino, 2018

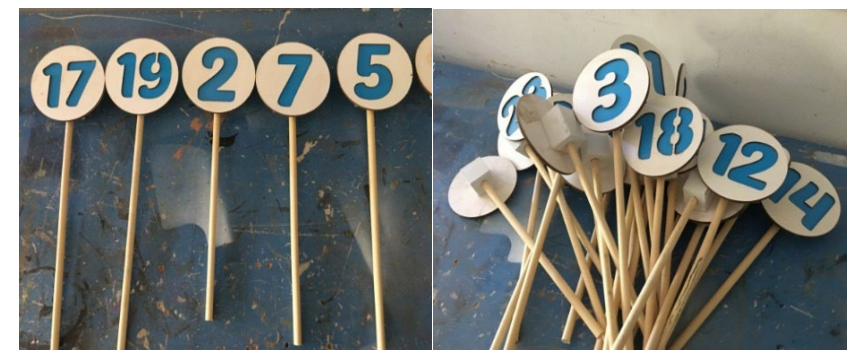

Figura 14- Números para cada planta na horta Fonte: Pazmino, 2018 
O painel da horta e os números foram instalados no NDI.

Também foi feito um jogo para que crianças possam entender a importância de separar os resíduos pelos tipos, metal, plástico, vidro, orgânicos. Este sistema é um padrão mundial e já que na UFSC por uma questão de logística não foi implantada está separação, o Jogo foi levado e doado para a Creche Nossa Senhora Aparecida localizada na Rua Dep. Antônio Edu Vieira, SN, Pantanal na cidade de Florianópolis.

A creche pertence a rede municipal e contava com 97 alunos. $O$ jogo foi feito para crianças de 5 a 6 anos. A figura 15 mostra o jogo (painel metálico, peças imantadas, uma cartilha informativa). E o jogo sendo utilizado pelas crianças da creche.

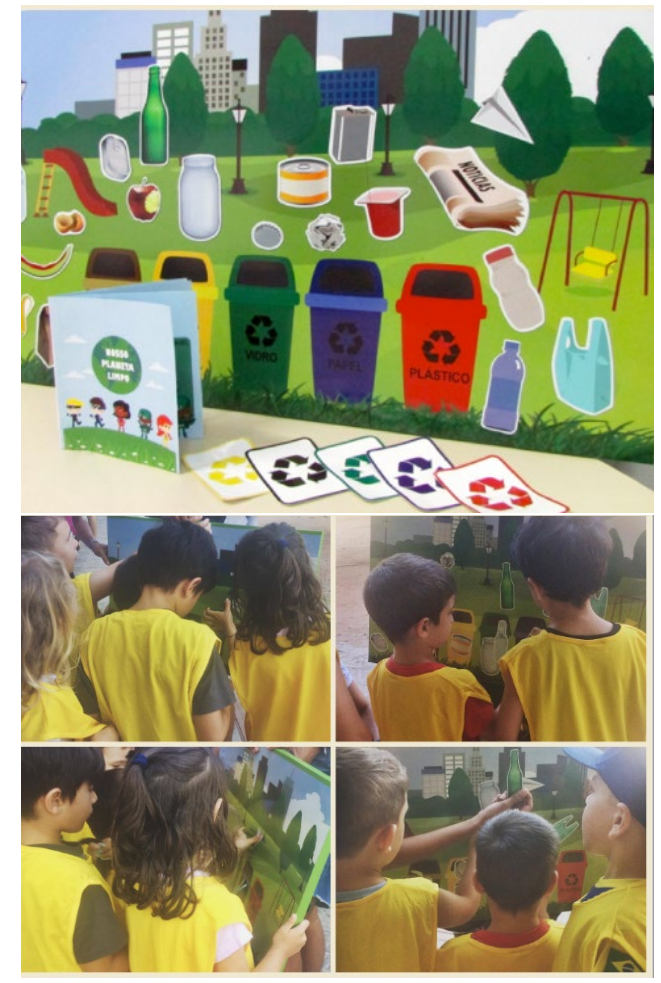

Figura 15- Jogo reciclaeduc

Fonte: Pazmino, 2018

Também teve um projeto que envolveu a diagramação e ilustração de uma cartilha sobre o Desafio Lixo Zero, elaborada em conjunto com o Núcleo de Educação Ambiental da Universidade Federal de Santa Catarina - NEAmb.

A cartilha Desafio Lixo Zero foi elaborada incorporando os aspectos estéticos, funcionais e conceituais desejados pela equipe para a criação de um material informativo e didático que auxiliasse na sensibilização para a diminuição de resíduos em escolas. Foi feito para ser distribuído fisicamente e em arquivo pdf. Para as escolas e IES onde é aplicado o projeto. A figura 16 mostra o resultado do livro físico e a figura 17 o digital.

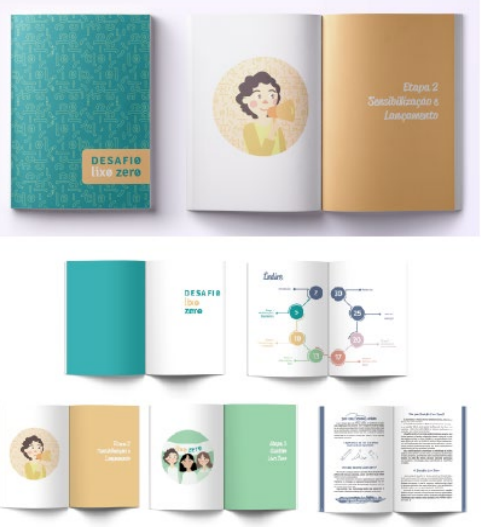

Figura 16- Livro físico "Desafio do lixo zero" Fonte: Krause e Quaresma, 2017

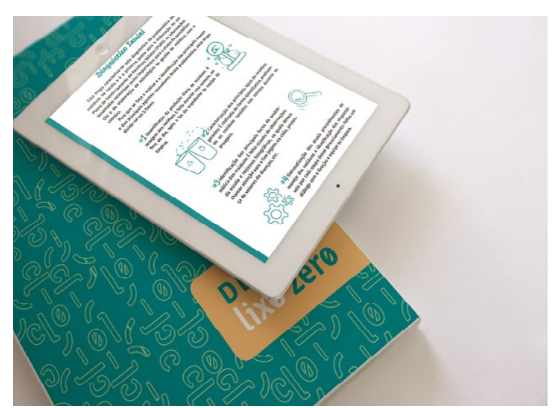

Figura 17-Livro digital e físico Fonte: Krause e Quaresma, 2017

Entre os projetos realizados pelos alunos, houve trabalho com os catadores da associação de coleta solidária e foram desenvolvidos diversos jogos de sensibilização para uma gestão de resíduos mais consciente em diversos ambientes da comunidade como creches e escolas. Os materiais (entre objetos e material gráfico) foram entregues na comunidade.

Percebe-se nos resultados que o design social se manifesta em ações de extensão como a mostrada neste artigo. Mostrando um eco as palavras de Margolin, 2004.

Um modelo social de prática de design se mostra cada vez mais necessário, e nós estamos esperançosos que designers preocupados, pesquisadores em design, profissionais de assistência e educadores do design encontrem uma maneira de tornar este modelo possível! (MARGOLIN, 2004, p. 30,

O processo de design com vistas à dimensão social e ambiental é um fenômeno de criação e produção de artefatos que podem beneficiar a sociedade, segundo uma visão ativa, dinâmica e participativa de métodos para o exercício de um fenômeno criativo. Trata-se de um sistema aberto de ensino e aprendizagem, em que há troca de visões e problemas do mundo, do sentir e do agir no desenvolvimento de soluções. 
A curricularização da extensão surge porque a extensão não pode ser entendida como um apêndice, de forma isolada, entre as funções da universidade. Ela deve ser incluída como parte indissociável do ensino e da pesquisa nas práticas pedagógicas de todos os currículos. A educação precisa ser integral e não fragmentada (ANTUNES e PADILHA, 2010).

Temos que lembrar que a Extensão Universitária é a ação da Universidade junto à comunidade que possibilita o compartilhamento, com o público externo, do conhecimento adquirido por meio do ensino e da pesquisa desenvolvidos na instituição. Por este motivo que a relação de ensino e extensão pode gerar soluções criativas com um viés sustentável.

\section{CONCLUSÃO}

O artigo mostrou alguns dos resultados da ação de ensino-aprendizagem com o projeto de extensão "Gestão de Resíduos da UFSC". A problemática do descarte de resíduos precisa de soluções para reduzir a geração e para promover o descarte adequado reduzindo a quantidade de resíduos que são destinados ao aterro sanitário ou lixões.

O projeto do coletor externo mostrado no artigo, ainda não foi produzido e espera-se que se concretize já que beneficiará todas as pessoas que utilizam e frequentam o campus. Os projetos para o NDI tanto na criação do painel e um sistema para conhecer todas as 24 plantas da horta como o jogo informando sobre resíduos de forma lúdica foram confeccionados e entregues.

$\mathrm{O}$ artigo mostrou a ação de design em um projeto de extensão em que a participação de alunos da disciplina de metodologia de projeto por meio da prática de projeto como processo de ensino-aprendizagem permitiu o desenvolvimento de diversos materiais dos quais quatro foram apresentados neste artigo.

Salienta-se a importância da participação de bolsistas e voluntários do projeto de alunos de fases mais avançadas auxiliando no desenvolvimento e na materialização, assim como a participação de um projeto de conclusão de curso. Um aspecto que merece reconhecimento é a execução do material realizada no Laboratório Pronto 3D da UFSC.

Embora as ações extensionistas são um caminho possível para beneficiar o público externo, existem aspectos que devem ser construídos e normatizados pela universidade.

Assim como, é necessário que a gestão da universidade ofereça condições para sua efetivação por meio de: Formas de financiamento, programas de bolsas para estudantes; valorização da participação do docente nas ações extensionsitas; transporte; materiais de consumo; apoio logístico; segurança de professores e estudantes entre outros.

\section{AGRADECIMENTOS}

A PROEX UFSC e ao Laboratório de Fabricação Digital Pronto 3D.

\section{REFERÊNCIAS}

ANTUNES, Ângela; PADILHA, Paulo Roberto. Educação cidadã, educação integral: fundamentos e práticas. São Paulo: Instituto Paulo Freire, 2010.

ABRELPE. Panorama dos resíduos sólidos no Brasil

2020. Disponível em: https://abrelpe.org.br/panorama/ Acesso em: 5 de novembro, 2020.

COMCAP. Gestão dos Resíduos em Florianópolis: Florianópolis: Comcap, 2019. Color. Disponível em: <http://www.pmf.sc.gov.br/arquivos/arquivos/ pdf/28_03_2012_12.14.43.479674c6336c7d401fc5b3775836ac3a.pdf>. Acesso em: 5 de novembro, 2020.

COMPANHIA DE MELHORAMENTO DA CAPITALCOMCAP (Florianópolis). Plano de Gerenciamento de

Resíduos Sólidos- PGRS: Município de Florianópolis/ SC. Florianópolis, 2019. Disponível em: http://www. pmf.sc.gov.br/entidades/comcap/index.php?cms=plano+de+gerenciamento+de+residuos+solidos \&menu=8. Acesso em: novembro de 2020.

BRASIL. Decreto n. ${ }^{\circ} 12.305$, de 2 de agosto de 2010, institui a Política Nacional de Resíduos Sólidos; altera a Lei no 9.605, de 12 de fevereiro de 1998; e dá outras providências. Diário Oficial [da] República Federativa do Brasil, Brasília, DF, p.3. Seção 1. Diário Oficial da União (DOU) de 03 de agosto de 2010.

BRASIL. Decreto n. ${ }^{\circ}$.940, de 25 de outubro de 2006, institui a separação dos resíduos recicláveis descartados pelos órgãos e entidades da administração pública federal direta e indireta, na fonte geradora, e a sua destinação às associações e cooperativas dos catadores de materiais recicláveis, e dá outras providências. Diário Oficial [da] República Federativa do Brasil, Brasília, DF.

BROWN, Tim. Design Thinking: Uma metodologia poderosa para decretar o fim das velhas ideias. Rio de Janeiro: Elsevier Editora Ltds, 2009. 249 p.

KRAUSE, Laís; QUARESMA, Juliana. Cartilha de formação desafio lixo zero. Relatório de projeto da disciplina Metodologia de projeto do curso de design da UFSC. 2017.

NEMER, Gabriel. Cata-quí.: Jogo para separação de resíduos. Relatório de projeto da disciplina Metodologia de projeto do curso de design da UFSC. 2018. 
MARGOLIN, Sylvia; MARGOLIN, Victor. A "Social Model" of Design: issues of practice and research. 2002. Disponível em: http://www.yorku.ca/wsywong/ course/ysdn3104_04/margolinsocial.pdf >. Acesso em: 19 maio 2013.

PAZMINO, Ana Veronica. Relatório de projeto de extensão. Proex. 2018

PRÉVE, Marina Koerich. Coletor de Resíduo Binário Para o Campus da Universidade Federal de Santa Catarina. Projeto de conclusão do Curso de Design. 2017.

VIANNA, Mauricio. et al. Design Thinking: Inovação em negócios. MJV, 2012.

\section{AUTORES}

ORCID: 0000-0001-7669-8650

ANA VERONICA PAZMIN0, Dra. | Universidade Federal de Santa Catarina | Design de Produto | Florianópolis, SC - Brasil | Correspondência para: Av. Madre Benvenuta 322 ap 816 Trindade CEP: 88036-500 | e-mail: anaverpw@gmail.com

\section{COMO CITAR ESTE ARTIGO}

PAZMINO, Ana Veronica. Aplicação De Projetos De Design Na Gestão De Resíduos Da Ufsc. MIX Sustentável, [S.I.], v. 7, n.4, p. 61-70, set. 2021. ISSN 24473073. Disponível em:<http://www.nexos.ufsc. br/index.php/mixsustentavel>. Acesso em: dia mês. ano. doi:https://doi.org/10.29183/2447-3073.MIX2021. v7.n4.61-70.

DATA DE ENVI0: 06/05/2021

DATA DE ACEITE: 07/05/2021 